\title{
Erratum to: The therapeutic efficacy of intensive medical therapy in ameliorating high-density lipoprotein dysfunction in subjects with type two diabetes
}

\author{
Sangeeta Kashyap ${ }^{1 *}$, Karim Kheniser ${ }^{1}$, Ling Li ${ }^{2}$, James Bena ${ }^{3}$ and Takhar Kasumov ${ }^{4,5^{*}}$
}

\section{Erratum}

After publication of the original article [1], it came to the authors' attention that a source of funding was not disclosed in the Declarations section of the paper. The study was in part supported by the American Diabetes Association (1-15-IN-31). The Funding section of the original article should have acknowledged this grant.

\footnotetext{
Author details

'Departemnt of Endocrinology and Metabolism, Cleveland Clinic, 9500 Euclid Avenue, Cleveland, OH 44195, USA. ${ }^{2}$ Department of Core Facilities, Cleveland Clinic, 9500 Euclid Avenue, Cleveland, OH 44195, USA. ${ }^{3}$ Department of Quantitative Health Sciences, Cleveland Clinic, 9500 Euclid Avenue, Cleveland, OH 44195, USA. ${ }^{4}$ Department of Hepatology, Cleveland Clinic, 9500 Euclid Avenue, Cleveland, OH 44195, USA. ${ }^{5}$ Present address: Department of Pharmaceutical Sciences, Northeast Ohio Medical University, 4209 St. R. 44, PO Box 95, Rootstown, OH 44272, USA.
}

Published online: 09 November 2016

\section{Reference}

1. Kashyap S, Kheniser K, Li L, Bena J, Kasumov T. The therapeutic efficacy of intensive medical therapy in ameliorating high-density lipoprotein dysfunction in subjects with type two diabetes. Lipids Health Dis. 2016;15:141. doi:10.1186/s12944-016-0314-4.

\footnotetext{
*Correspondence: Kashyas@ccf.org; tkasumov@neomed.edu

'Departemnt of Endocrinology and Metabolism, Cleveland Clinic, 9500 Euclid Avenue, Cleveland, OH 44195, USA

${ }^{4}$ Department of Hepatology, Cleveland Clinic, 9500 Euclid Avenue, Cleveland, $\mathrm{OH} 44195$, USA
} 